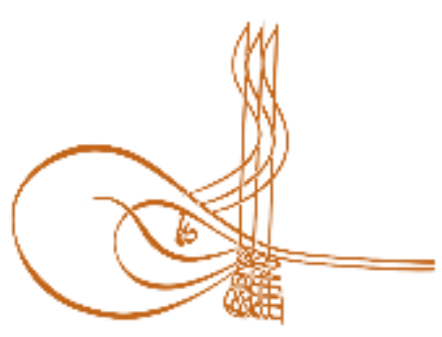

www.turkishstudies.net/social
Turkish Studies - Social Sciences

eISSN: $2667-5617$

Research Article / Araștırma Makalesi

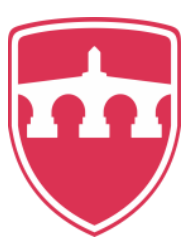

INTERNATIONAL BALKAN

UNIVERSITY Sponsored by IBU

\title{
Popüler Kültür, Adli Bilimler ve Dizi Filmler Bağlamında Yeni Bir Kavram: Kurgusal Atıf"
}

\author{
A New Concept in the Context of Popular Culture, Forensic Sciences and Film series: Fictional \\ Attribution
}

\author{
Sefer Darıcı* $^{* *}$ Vahdet Özkoçak ${ }^{* * *}$
}

\begin{abstract}
The developments in digital technologies have enabled the relevant content to reach the audience of movies and series through many different tools. The availability of films and TV series without time and space restrictions has also changed the content used in these technologies proportionally. The film and TV series sector produces for the masses on the one hand and continues to nurture and diversify the popular culture on the other. It is important not only to reach the audience but also to have a lasting effect on them. This has become imperative for the reproduction and continuity of the relevant content. In this respect, it seems that the success of the content depends on supporting it with popular cultural elements and at the same time preserving it as a whole. From this perspective; It should be ensured that the viewer perceives the scenes as a whole on the screen he is looking at and is convinced by the influence of the popular one. Thus, the viewer's view that the content is real should be able to replace fiction. Advances in the series and film industry have led to many different ways of presenting forensic cases. The effects of these broadcasts, which have different effects on the audience, on daily life are discussed. In this study, it was investigated how the presentation of characters and forensic events in crime-themed films had an impact on the audience. In addition, the contribution of popular culture to this has been examined. The effects of four crime-themed movies on the audience were investigated. A total of 284 comments made on the internet of the series followers were analyzed. The results are gathered under 3 different themes under "Threshold of Reality", "Emotional Expression" and "Fictional Attribution".
\end{abstract}

Structured Abstract: Introduction Some films and TV series related to crime and crime are productions in which different forms of violence are presented with different shooting techniques and in a realistic way, and

\footnotetext{
* Bu çalışmanın özeti 3-5. 11. 2019 tarihleri arasında İstanbul'da düzenlenen CUDES 2019: X. International Congress on Current Debates in Social Sciences’ta sözlü bildiri olarak sunulmuştur.

** Dr. Öğr. Üyesi, Sivas Cumhuriyet Üniversitesi, Cumhuriyet MYO, Pazarlama ve Reklamcilık Bölümü Asst. Prof. Dr., Sivas Cumhuriyet University, Cumhuriyet Vocational Scholl, Department of Marketing and Advertising ORCID 0000-0002-3630-4511

seferdarici@gmail.com

**** Dr. Öğr. Üyesi, Hitit Üniversitesi, Fen-Edebiyat Fakültesi, Antropoloji Bölümü

Asst. Prof. Dr., Hitit University, Faculty of Science and Letters, Department of Anthropology

ORCID 0000-0002-4603-2548

vahdetozkocak@gmail.com

Cite as/ Atıf: Darıcı, S., Özkoçak, V. (2020). Popüler kültür, adli bilimler ve dizi filmler bağlamında yeni bir kavram: kurgusal atıf, Turkish Studies - Social, 15(2), 127-144. https://dx.doi.org/10.29228/TurkishStudies.40605

Received/Geliş: 16.01.2020

Accepted/Kabul: 25 February/Şubat 2020

Checked by plagiarism software

Copyright (C) INTAC LTD, Turkey

Published/Yayın: 29 February/Şubat 2020

CC BY-NC 4.0
} 
fiction and reality are given in intricate and indistinguishable forms. These productions, on the one hand, saturate one's subconscious violent motive from a Freudian point of view, while also feeding the fantasy of violence cognitively by giving it in a popular form of entertainment.

Forensic events and the way forensic sciences are presented may cause perceptual differences of viewers in crime-themed films and series. Popular culture, detaching real events from its context, with a fictional design, turns the reality into different looks. It shows that everything for this popular culture is seen as secondary elements that serve this purpose. Therefore, with the popular culture perspective, forensic events and forensic science can be seen as factors that only contribute to the entertainment element and increase the impact on the audience. Contrary to the goals and objectives of science, it can have a greater impact on society than science by using science. This effect turns into a form where fiction and reality are not different and almost substitute each other. It may be possible to see the impact of crime-themed films and TV series on the audience in their different interpretations of the audience.

\section{Forensic Sciences}

The Forensic Sciences field evaluates the data obtained from crime and forensic events and transforms the results of these data into evidence that the courts can use in order to resolve the crime (Akyel et al., 2019). It has the feature of multidisciplinary working with many branches of science in terms of manifesting justice. Crime diversity in the field of forensic science is increasing day by day, but in TV series and movies, this variety and crime are removed from its context, transferred in different ways and sacrificed to popular culture. Especially sexual abuse, migration, terrorism and smuggling crimes bring new dimensions to the forensic science field.

\section{Popular Culture}

From a Freudian point of view, it can also be said that in the films about crime and crime, the viewers' tendencies regarding violence and violence that cannot be satisfied in real life are satisfied through the screen. Individuals, on the one hand, satisfy the psychological subconscious need and, on the other hand, enjoy fun presentations. This situation, in which one is not consciously aware of himself, can be seen as one of the most important cognitive weapons of popular culture.

\section{Methodology}

In this study, a mixed approach based on qualitative research based on media content (Riffe et al., 2005), case study (Christensen et al., 2015) and content analysis method (Cohen, 1963) were used.Veri Toplama ve Analiz

\section{Results}

In this study, the comments of the audience of 5 popular series known for their crime and crime content were analyzed and 3 main themes were found:
1- $\quad$ Threshold of Reality
2- Emotional Expression
3- $\quad$ Fictional Attribution

\section{Theme-1: Threshold of Reality}

The concept of the 'Threshold of Reality' refers to the perceptual boundary between the real world and simulated reality. It is the limit that a simulated reality must pass in order to replace the 'real truth' perceptually (Darıc1, 2015: 198). In the comments made by some viewers about the series, it was observed that they did not distinguish between real life and the fictional format of the series, identifying real-life with images related to fictional events, or thinking that the characters reflect real life.

\section{Theme-2: Emotional Expression}

In the analysis of the comments, it was seen that the audience used emotional expressions such as crying, excessive anger, excessive joy, love, or 'attachment to the severity that would break with real-life'. It was also noted that the majority of the viewers who commented on all of the series examined had statements that they felt in desideratum after the series ended. In the comments of some of the viewers about the killing 
scenes played by the character, it was seen that they identified themselves with the killer character in the series and associated them with real life.

\section{Theme-3: Fictional Attribution}

With the concept of fictional attribution; it refers to the fact that the viewers attribute the content, events, and characters presented to them fictionally to real life. The concept describes how people's thoughts, attitudes change in this direction, and that their cognitive structures and behaviors are affected to a degree that affects the flow of their daily lives. In this sense, the concept has been used to meet references to real-life from the fictional world.

\section{Conclusion and Discussion}

It was seen that most of the viewers who commented had difficulty in distinguishing between real life and fiction by being influenced by the characters, scenes and plot of the movies. Many comments have shown that it is believed that real life is reflected in a series of films. In addition, it was observed that the idea that many things that could not be realized in real life could only be realized through a series of movies was dominant. From the comments in this context, it can be thought that the boundary (reality threshold) between real life and simulated reality has been eroded and even started to be used instead of reality.

In the analyzed comments, it was seen that the viewers used the expressions of crying, excessive anger, excessive joy, love or 'connecting in a way to break from real life'. In the comments on the series, it was noted that more than one audience used statements that they felt lonely or in desideratum after the films they watched were finished. In the series, it is seen that they identify themselves with the characters who played the guilty person. In addition, by expressing empathy with the character who played the role of the killer, expressions were found that even killing was justified and supported.

In the study, the expressions that the viewers attributed the content, events, and characters presented to them fictionally to real-life attracted attention. In this respect, it was analyzed in the comments that they convey the characters, scenes or plot that they watch fictionally to real life and even their thoughts and attitudes change in this direction. In addition, it was observed that they expressed that their cognitive structures and behaviors were affected to the extent of their daily lives. In this sense, the concept of "fictional attribution" was introduced and it was aimed to meet attributions which to real-life from the fictional world. Fictional attribution concept refers to transferring and attributing the elements related to fiction to real life, as the difference between fiction and reality disappears.

Keywords: Forensic Science, Popular Culture, Film, Series, Criminal

Öz: Dijital teknolojilerdeki gelişmeler, ilgili içeriğin birçok farklı araçla film ve dizi izleyicilerine ulaşmasını sağlamıştır. Zaman ve alan kısıtlaması olmaksızın filmlerin ve TV dizilerinin kullanılabilirliği de bu teknolojilerde kullanılan içeriği orantılı olarak değiştirdi. Film ve TV dizileri sektörü bir yandan kitleler için üretirken, diğer yandan popüler kültürü beslemeye ve çeşitlendirmeye devam ediyor. Sadece izleyiciye ulaşmak değil, aynı zamanda onlar üzerinde kalıcı bir etki yaratmak da önemlidir. Bu, ilgili içeriğin çoğaltılması ve sürekliliği için zorunlu hale gelmiştir. Bu bakımdan, içeriğin başarısının onu popüler kültürel unsurlarla desteklemeye ve aynı zamanda bir bütün olarak korumaya bağlı olduğu görülmektedir. Bu perspektiften; İzleyicinin, sahneleri baktığı ekranda bir bütün olarak algılaması ve popüler olanın etkisi ile ikna edilmesi sağlanmalıdır. Bu nedenle, izleyicinin içeriğin gerçek olduğuna ilişkin görüşü, kurgunun yerini alabilmelidir. Dizi ve film endüstrisindeki gelişmeler, adli vakaların birçok farklı şekilde sunumuna yol açmıştır. İzleyiciler üzerinde farklı etkiler bırakan bu yayınların gündelik hayat üzerindeki etkileri tartışılmaktadır. Bu çalışmada, suç temalı filmlerde, karakterlerin ve adli olayların sunuluş biçiminin izleyici üzerinde nasıl bir etki bıraktığı araştırılmıştır. Ayrıca popüler kültürün bundaki katkısı da irdelenmiştir. Dört suç temalı dizi filmin izleyiciler üzerindeki etkisi araştırılmıştır. Dizi takipçilerinin internet üzerinde yapılan toplam 284 yorumunu analiz edilmiştir. Sonuçlar 3 farklı tema olarak "Gerçekliğin Eşiğii", "Duygusal İfade" ve "Kurgusal Atıf" altında toplanmıştır.

Anahtar Kelimeler: Adli Bilimler, Popüler Kültür, Film, Dizi, Suç 


\section{Giriş}

Dijital teknolojilerde meydana gelen değişimler izleyiciye çok farklı yollarla ulaşılabilmesine firsat sağlamıştır. Bir filmi, bir diziyi zaman ve yer kısıtlaması olmaksızın izleyebilme imkânı sunan bu teknolojilerle birlikte içerik de değişime uğramıştır. Film ve dizi sektörü bir yandan kitleye yönelik üretim yaparken bir yandan da popüler kültürü beslemekte ve çeşitlendirmektedir. İzleyiciye sadece ulaşmak değil, onda kalıcı etki bırakabilmek sinema filminin veya dizinin devamı için de önemlidir. $\mathrm{Bu}$ açıdan, içeriğin başarısı popüler kültür öğeleriyle desteklenmesine ve aynı zamanda popüler kültürü destekleyen yönünün bir bütün içerisinde korunmasına da bağlıdır. İzleyici baktığı ekranda sahneleri bir bütün olarak algılamalı, popüler olanın etkisiyle ikna olmalı, içeriğin gerçek olduğuna ilişkin kanısı kurgunun yerine geçebilmelidir.

Suç ve suça ilişkin bazı film ve diziler, şiddetin farklı biçimlerinin, farklı çekim teknikleriyle gerçeğe yakın bir şekilde sunulduğu, kurguyla gerçek olanın iç içe ve ayırt edilemeyecek formlarda verildiği yapımlardır. Bu yapımlar bir yandan kişinin bilinçaltındaki şiddet güdüsünü Freudyan bir bakış açısıyla doyurmakta, bir yandan da popüler bir eğlence formunda vererek, şiddetin fantazyasını bilişsel olarak beslemektedir.

Suç temalı film ve dizilerde, adli olaylar ve daha geniş anlamda adli bilimlerin kurgulanış şekli de algılayış farklılıklarına neden olabilmektedir. Gerçek olayları bağlamından kopararak, kurgusal tasarımla, seyirlik farklı görünümlere dönüştüren popüler kültür için hemen hemen her şey bu amaca hizmet eden tali unsurlar olarak görülebilir. Bu nedenle adli olaylar ve adli bilimler, popüler kültür için sadece eğlence unsuruna katk1 sağlayan ve izleyici üstünde etkiyi arttıran faktörler olarak görülebilir. Bilimin amaç ve hedeflerine aykırı olarak, bilimi kullanarak toplum üzerinde ondan daha fazla bir etki yaratabilir. Bu etki kurgu ile gerçek olanın farkının kalmadığı ve birbirleri yerine ve birbirleri için kullanıldığ 1 bir forma dönüşmektedir.

Suç temalı filmler ve dizilerin izleyici üzerindeki etkisini, yaptıkları yorumlarda farklı biçim ve formatlarda görmek mümkün olabilir. Bu çalışmada izleyenler üzerinden ve genel olarak toplum üzerindeki bu etkinin yansımasının nasıl olduğu, film ve dizilere ilişkin yapılan yorumlar aracılığıyla ortaya konması amaçlanmıştır. Bu nedenle ilk önce adli bilimler ve popüler kültüre ilişkin literatür incelendikten sonra suç ve suça ilişkin popüler dizilerden yorumlar analiz edilmiştir.

\section{Adli Bilimler}

Adli Bilimler alanı suç unsuru barından adli özellikteki olaylarda elde edilen verileri değerlendirerek, bu verilerin sonuçlarını suç olayını çözümleyecek şekilde hukukun yararlanabileceği deliller haline getirmektedir (Akyel vd., 2019). Adaletin tecelli etmesi açısından birçok bilim dalı ile multidisipliner çalışma özelliğine sahiptir. Adli Bilimler alanı fen bilimleri, sosyal bilimler ve kriminalistik bilimlerini kapsamaktadır (Bolat ve Mantar, 2019).

Dizi ve filmlerde ölen kişiye ait kimliklendirmenin, cesede ilişkin çeşitli ölçümlerin farklı bir biçimde sunulduğunu ve yanlış algılamaya sebep olabileceği söylenebilir. Burada Adli Bilimler içerisinde yer alan Adli Antropoloji alanı devreye girer. Adli Antropoloji, kişiye ait iskelet kalıntısından ya da yumuşak doku üzerinden kimliklendirme yaparak adli vakaları çözüme kavuşturmaktadır. Kimliklendirme işlemini olay yerinden elde edilen iskelet materyali üzerinden boy, yaş, cinsiyet, etnik köken, patolojik bulgular, ölüm zamanının belirlenmesi ile gerçekleştirmektedir (Çetli vd., 2019).Adli Antropoloji alanı, içerisinde iki önemli teknik barındırmaktadır. $\mathrm{Bu}$ tekniklerden olan Antropometri tekniğinde cesetin boy uzunluğu, büst yüksekliği gibi değerleri antropometrik ölçümler ile belirlemektedir. Somatoskopi tekniğinde ise kimliklendirme işlemi yumuşak doku üzerinden yapılmaktadır. Kimliklendirme için Somatoskopi ve Antropometrik teknikler üzerinden elde edilen veriler adli vakaların çözümlenmesi aşamasında çok önemli olmaktadır (Özkoçak vd., 2017). 
Adli Bilimler alanında olayın çözüme kavuşturulmasında kimliklendirme çalışmalarının önemi büyüktür. Suçlu ya da maktule ait veriler üzerinden kimliklendirme çalışmaları yapılmaktadır. Kişiye ait her türlü veri kişisel veri olarak adlandırılmakta özellikle son yıllarda biyometrik olarak adlandırılan veriler önem kazanmaktadır. Biyometrik veri, kişiye ait fizyolojik ya da davranışsal olarak ölçülebilen verileri kapsamaktadır. Yüz, retina, iris, parmak izi, ses tanıma fizyolojik veriler olarak adlandırılırken imza, tuş vuruş sesi gibi veriler davranışsal veriler olarak adlandırılmaktadır (Çetli ve Özkoçak, 2018).

Yine dizi ve filmlerde çok hızlı ve gerçekle bağdaşmayan şekilde yüz tanımanın kullanıldığı sahneler yer almaktadır. Yüz tanıma adli olayların çözümlenmesi açısından son derece önemlidir. Yüz verisi insanın tanınmasını kolay kılmaktadır. CCTV kameralarından elde edilen veriler ile kişinin tanımlanması mümkün olmaktadır. Yüz biyometrisi gündelik hayat içerisinde bilinen en yaygın veridir. Bu sebeple adli vakalarda sonuca ulaşmak için sıklıkla kullanılmaktadır (Özkoçak ve Özdemir, 2017). Bunun yanı sıra yüz verisi için yeniden yüzlendirme teknikleri kullanılmaktadır. Yeniden yüzlendirme, kayıp veya kimliği belli olmayan bir kişinin yüz şeklinin yeniden tasvir edilmesidir. Yeniden yüzlendirme çalışmaları yüz üzerinde bulunan anatomik noktalardan (landmark) yüzün tahmin edilmesi işlemidir. Yeniden yüzlendirme çalışmalarında Kraniyofasiyal Süperimpozisyon Tekniği, İki Boyutlu Yeniden Yüzlendirme Tekniği (2D), Üç Boyutlu Yeniden Yüzlendirme Tekniği (3D) olmak üzere üç teknik bulunmaktadır. Özellikle son zamanlarda 3D metodu sıklıkla kullanılmaya başlamıştır (Koç, 2019).

Son yıllarda dizi ve filmlerde göç, cinsel istismar, terör ve kaçakçllık olaylarının da yoğun bir şekilde işlendiği görülmektedir. Adli bilimler alanında suç çeşitliliği gün geçtikçe artış göstermektedir ancak dizi ve filmlerde bu suç çeşitliliği ve özü, bağlamından koparılarak, farklı şekillerde aktarılmakta ve popüler kültüre kurban edilmektedir. Özellikle cinsel istismar, göç, terör ve kaçakçılık suçları adli bilimler alanına yeni boyutlar kazandırmaktadır. Göç, kişi veya grupların ekonomik, dini, sosyal, siyasi sebeplerden ötürü yer değiştirmesi olarak adlandırılmaktadır. İç göç; ülke içerisinde yaşanan yer değişikliği, dış göç; ülke dışına yapılan yer değişikliği olarak tanımlanmaktadır. Yaşanan göç hareketliliği terör, insan kaçaklığı gibi suçların artışına zemin hazırlamaktadır (Taşkın, 2019). Diğer yönden Adli Bilimler alanında büyük öneme sahip bir suç türü de cinsel istismar suçudur. Cinsel İstismar suçu; çocuğun yetişkin tarafindan cinsel tatmini için kullanılmasıdır. Mağdur çocuk üzerinde sonraki dönemleri açısından ciddi bir psikolojik yıkıma sahiptir. Cinsel istismar içerisinde değerlendirilen fiziksel istismar, 18 yaşından küçük çocuklarda yetişkin tarafindan bedenen ve ruhen zarar verilmesi anlatılırken, duygusal istismarda ise bahsedilen konu çocuğun etrafındaki kişiler tarafından çocuğun kişisel gelişimini zedeleyen, duygusal gelişimi engelleyen durumlardır (Tekeli ve Çetli, 2019). Son zamanlarda cinsel istismar vakalarının çözümünde Adli Görüntü analizinden yararlanılmaya başlanmıştır. Adli Görüntü analizi uzmanları tarafindan elde edilen delillerin ve görüntülerin yorumlanması ile olaylar çözüme kavuşma oranları artmıştır. Adli Bilimler alanında yaşanan her türlü yeni gelişme olayların aydınlatılmasında büyük önem arz etmektedir. (Mantar ve arkadaşları, 2019).

\section{Popüler Kültür}

Popüler kültürün literatürde herkes tarafindan kabul edilen ortak bir tanımına rastlanılmamıştır. Ancak Williams popüler kültürden bahsederken dört farklı tanımın önemine dikkat çeker.

"Bunlar, 'çok sayıda insan tarafından kabul gören', 'bayağı/sıradan nitelikte olan', 'bilinçli bir şekilde insanların favorisi konumuna gelmesi için tasarlanan' ve "esasen insanlar tarafindan kendileri için yapılmakta olan“ şeklinde sıralanmaktadır” (Storey’den akt. Tellan, 2016, p.148)

Özünde eğlenceye, vakit geçirmeye yönelik olan popüler kültürü haz duygusu güdülemektedir. İnsanları düşsel bir rahatlama sunan bu kültür, gerçek hayatta ulaşılamayan veya doyurulması mümkün olmayan ihtiyaç veya hazların tatminini hedefler (Arık, 2009: 27). Suç ve 
suça ilişkin filmlerde, izleyiciye Freudyan bir bakış açısıyla, gerçek hayatta doyurulması mümkün olmayan şiddet ve şiddete ilişkin eğilimlerin, ekran yoluyla tatmininin sağlandığı da söylenebilir. Kişi bir yandan psikolojik olarak bilinçaltında yatan ihtiyacı tatmin etmekte bir yandan da eğlenceli sunumla haz almaktadır. Kişinin bilinçli olarak kendisinin dahi farkında olmadığı bu durum popüler kültürün en önemli bilişsel silahlarından biri olarak görülebilir.

Suç ve suça ilişkin bu yapımların birçoğunda kurgusal yapı, izleyicinin kendisini olay örgüsü içinde konumlandırabileceği veya gündelik hayat akışında anlamlandırabileceği bir durumun içine çeker. İzleyici ekranda kendisine sunulan farklı bir ülkenin suç veya suça ilişkin çerçevesi olsa da, bunu kendi kültürel anlam dünyasına uyarlar. Özkan (2006: 32) bu durumu şu şekilde ifade etmektedir:

“...popüler kültürün oluşmasında ortamın varlığında izleyicinin kendini bulması ve bunu anlamlandırması önemlidir. Bu tür diziler izleyicilerine bir anlam dağarcığı sunar. Esasen bu anlam dağarcığı izleyicilerin kendi seçimlerini kendilerinin yapabildikleri, sonra da bu seçimleri kendi kültürlerine uydurabildikleri bir anlamlar süpermarketidir. İzleyicilerin sağlık ve mutluluk arası ilişkilerden, ticari ilişkilerden, cinsel ilişkilerden, mahremlerinden kendi anlamlarını üretmeye imkân sağlar. Dolayısıyla bu filmler değişik popüler kültürlerin oluşturulabileceği göreceli bir kaynak bankası konumundadır".

Popüler kültür, teknoloji eliyle bir sahte bilinç yaratmakta, parametrelerini dayatmakta (Marcuse, 1964, xliv-26) ve zamanla tekrar ederek kendini kabul ettirmektedir. Sahte bilinç, insanların olaylara ve olgulara bakış açılarına yansımakta, tutum ve davranışlarına da yön vermektedir. Bu aynı zamanda bireylerin bilinçaltlarında yatan kalıpların ve arketiplerin de çağrışımsal olarak zihne ulaştırdığı anlamları değiştirmektedir. Statüler, kimlikler ve onlara yüklenen anlamlar değişebilmektedir. Popüler kültür hegemonik araçlarıyla bireyi çepeçevre kuşatmakta ve zihinsel yapısını yeniden inşa etmektedir. Bunu film veya dizilerde sürekli tekrar yoluyla verilen ve dünyanın herhangi bir yerindeki bireyin kişisel ve sosyal çevresini kuşatan imgeler yoluyla gerçekleştirebilmektedir. Benzer düşünen ve benzer hareket eden bir toplumun inşası, popüler kültürün sunduğunu kabul eden kitleler anlamına gelmektedir.

\section{Metodoloji}

Medya içeriklerinde nitel araştırma temelli karma bir yaklaşımın benimsendiği (Riffe et al., 2005) bu çalışmada durum çalışması (Christensen vd., 2015) ve içerik analizi yöntemi (Cohen, 1963) kullanılmıştır. Neumann'ın (2003, p. 219) ifade ettiği gibi analiz yapılırken içerikten anlaşılması gereken kelimeler, anlamlar olabileceği gibi resimler, semboller, fikirler, temalar veya mesajlar da olabilir.

Araştırmada bir ya da daha fazla durumun derinlemesine incelendiği, araştırmanın soru ve konularına dikkat çekmenin amaçlandığı çalışmalarda durum çalışması kullanılabilir (Christensen vd., 2015). Durum olarak bireyler, gruplar, kurumlar, kültürler vb. nitelendirilebileceği gibi kendisine has, özgün bir şey de durum olarak değerlendirilebilir (Patton, 1990).

Bir veya birden fazla duruma ilişkin verilerin çoklu kaynaklarla elde edilmesine imkan veren (Creswell, 2007) ve görgül bir araştırma yöntemi olan durum çalışması, çok yönlü ve derinlemesine bir inceleme yapar (Yıldırım\&Şimşek, 2013; Patton, 1990). Bu çalışmada ele alınan tek durum içerisinde, birden fazla alt analiz birimi (fotoğraf, video, metin vb.) söz konusu olduğundan, iç içe geçmiş tek durum deseni kullanılmıştır (Yin, 2003).

\section{Sinırlılıklar}

$\mathrm{Bu}$ çalışma, resmi yapımcı şirketin dışında, yasal olmayan şekilde yayın yapan 5 internet sitesi üzerinden yapılmıştır. Yorumlar bu siteler üzerinde yapılanlarla sınırlıdır. Seçilen ve analize tabi tutulan, nick name altındaki yorumları gerçek kişilerin yaptığı ve ifadelerinin gerçeği yansıttığı 
kabul edilmiştir. İzleyicilere ilişkin elde edilen bulgularla ilgili araştırmacıların değerlendirmeleri ise izleyicilerin internet sitelerinde yaptıkları yorumlarıyla sınırlı kalmıştır.

\section{Veri Toplama ve Analiz}

Çalışma verileri izleyicilerin dizi içerikleri ile ilgili yapmış oldukları yorumlara dayanmaktadır ve amaçlı örnekleme metoduyla toplanmıştır. İlk olarak verilerin toplanacağ internet siteleri belirlenmiştir. Bu amaçla dizilerin yayınlandığı resmi olmayan internet siteleri seçilmiştir. Bunun sebebi, bu sitelerde (dizilab, dizist, dizimag, dizipub, dizibox) izlenme oranlarının yüksek olması ve yorumcuların kimliklerinin açığa çıkma endișesinin olmamasıdır. Bilindiği gibi, diziler resmi olarak doğrudan tv kanalları, internet siteleri veya ilgili firmaların internet siteleri üzerinden, üyelik ve/veya ödeme işlemlerinin ardından izlenebilmektedir. Resmi olmayan internet sitelerinde ise farklı kullanıcı adları ve ödeme işlemleri olmaksızın (yasal olmayan şekilde) izletilmektedir. Bu nedenle, yorumların herhangi bir şekilde yorumlayıcının kimliğini ortaya çıkaracak, yorumun içeriğini etkileyecek işlem olmaksızın, daha rahat ve daha fazla yapıldığını varsaydığımız internet siteleri seçilmiştir.

İkinci olarak bu internet sitelerinin suç kategorisinde yer alan ve en fazla yorumlanan dizileri seçilmiştir. Bunlar Breaking Bad, Sherlock, The Wire, Dexter dizileridir. Ardından her iki araştırmacı tarafından tüm yorumlar okunmuş ve tanımlayıcı notlar alınmıștır. Daha sonra izleyicinin etkilendiğini belirttiği ve/veya araştırmacılar tarafından etkilendiği düşünülen yorumlar, iki araştırmacı tarafından birbirinden bağımsız olarak toplanmış ve ekran görüntüleri alınmıştır. Yorumların içerikleri ve yorumlayanların nick nameleri (word) dosyalarına ilgili dizi filmin ismiyle kaydedilmiştir. Toplamda 284 yorum için, 19 adet A4 sayfası (12 punto) metin dosyası oluşturulmuştur.

Her iki araştırmacı yapılan yorumları; tekrar etme, duygusal ifade kullanma, gerçeklik bağlamı ölçütlerine göre kodlamıştır. Ardından tüm veriler tekrar gözden geçirilmiş ve kategoriler haline getirilmiştir. Daha sonra araştırmacılar oluşturdukları bu kategorileri birbirleriyle karşılaştırmış ve nihai olarak 3 ana tema üzerinde karar verilmiştir.

\section{Bulgular}

Bu çalışmada, suç ve suça ilişkin içerikleriyle bilinen, 5 popüler dizinin izleyicilerinin yorumları analiz edilmiş ve 3 ana tema bulunmuştur:

1- $\quad$ Gerçeklik Eşiği (Threshold of Reality)

2- Duygusal İfade (Emotional Expression)

3- Kurgusal Atıf(Fictional Attribution)

Yorumlarda herhangi bir dilbilgisi düzeltmesi yapılmamıştır. Temalar doğrultusunda seçilen ilgili kısımlar olduğu gibi verilmiştir. Yorumlarda küfür içeren kısımlar nokta işareti kullanılarak kapatılmıştır.

\section{Tema-1: Gerçeklik Eşiği}

Gerçeklik eşiği (Threshold of Reality) kavramı gerçek dünya ile simüle edilen gerçeklik arasındaki algısal sınırı ifade eder. Simüle edilmiş bir gerçekliğin, zamanla algısal olarak 'gerçek gerçeğin' yerini alması için geçmesi gereken sınırdır (Darıc1, 2015:198). Dizilere ilişkin bazı izleyicilerin yaptıkları yorumlarda gerçek hayat ve dizilerin kurgusal formatı arasında fark gözetmediği, kurgusal olaylara ilişkin görüntülerle gerçek hayatı özdeşleştirdiği veya karakterlerin gerçek hayatı yansıttığını düşündükleri görülmüştür.

İzleyicilerin bazılarının, dizilerle ilgili, internet siteleri üzerinden yaptıkları, bu tema kapsamındaki bazı yorumları ve nick nameleri aşağıdadır: 


\section{1- Breaking Bad}

\section{Bloo23}

"Arkadaşlar şimdi dizinin en güzel özelliği gerçekçi olması. Yani adamın bütün duygularına odaklanıyorlar ve buda gerçekçi yapıyor. E buna alışınca da dizinin güzelliğini anlıyorsunuz zaten. Son bölümü izlememişseniz "Efsane" demeyebilirsiniz çünkü son bölümde duygu öyle bir verilmiş ki...” (www.dizilab.pw, Erişim Tarihi: 03.11.2019)

\section{Ase96}

“...ancak bu kadar hayatın içinden ve gerçekçi olabilirdi... hala düşünüyorum etkisindeyim..” (www.dizilab.pw, Erişim Tarihi: 03.11.2019)

\section{Azula}

“...dizide sürekli aksiyon ve cinsel içerik bekliyosanız,gerçek hayatta da gerçekleşebilecek bir karakter gelişimi görmek istemiyosanız izlemeyin tabi.” (www.dizilab.pw, Erişim Tarihi: 03.11.2019)

\section{İlkpsikolojikroman}

"Finalden sonra ciddi ciddi kendime gelemedim. Unutulmamas1 gereken hayat dersleri ve karakterlerle hayatımın hep bir köşesinde olacak dizi." (www.dizilab.pw, Erişim Tarihi: 03.11.2019)

\section{NeoTribal}

“...Ilgimizi ceken, heyecanlandiran, soka sokan, oldugumuz yerde ziplatan, dusunduren vb herseyin temelinde o sıkıcı dediginiz sahneler var. O detaylar da en ince ayrintisina kadar isleniyor hersey. Buda dizinin gercekligini arttiriyor. Bildiginiz hayatin kendisi. Diziyi efsanevi gormemizin en onemli nedenlerinden biri bu." (www.dizilab.pw, Erişim Tarihi: 03.11.2019)

\section{2- Dexter}

\section{@Elif B.}

"Dizideki psikolojik detaylar inanılmaz gerçekçi, ruhsal tasvirler cidden başarılı." (www.dizilbox.pw, Erişim Tarihi: 06.11.2019)

\section{Scofield Walter}

"Dexter.Adını duydugum zaman bile kalbim yerinden firlıyor. Bu dizi bir seri katil ve adli tıp çalışanının hayatını konu alıyor. Konusu gayet güzel, karakterler güzel, gerçekçilik konusunda bir kaç adım daha atılabilirdi..." (www.dizimag.pw, Erişim Tarihi: 04.11.2019)

\section{3- $\quad$ Sherlock}

\section{avatar aang}

"Sherlock'u bile psikolaga düşüren hayat bize neler neler yapmaz ki?" (www.dizilab.pw, Erişim Tarihi: 03.11.2019)

\section{g_ngsta}

"bitti ve ben bi saattir ekrana bakıp neye uğradımı anlamaya çalışıorum.." (www.dizilab.pw, Erişim Tarihi: 03.11.2019)

\section{Rüçhan Yavuzdemir}

"İnsanı da izledikten sonra zeki hissettirmiyor değil. Bazı zamanlar sherlock olduğumu bile hayal ediyorum?" (www.dizilab.pw, Erişim Tarihi: 03.11.2019) 


\section{4- The Wire}

\section{Sapphiens}

"Gerçeği esas alan bir dizi. Basit bir cümle ama izlerken ne demek olduğunu anlıyorsunuz. Kendi hayatınızdaki gerçekler ile nasıl yaşıyorsanız burada da başka hayatlardaki gerçekleri izliyorsunuz ki bu büyük bir başarı. Genelde dizilerde kendinizi, kim olmak istediğinizi veya olmak istemediğinizi görürsünüz ama burada başka hayatları görüyorsunuz. Başta da dediğim gibi bir masalı değil gerçeği izliyorsunuz.” (www.dizilab.pw, Erişim Tarihi: 03.11.2019)

\section{Cnrergen}

"Siyasetin, haberciliğin, hukukun, emniyetin tüm yozlaşmalarını ve düzenbazlıklarını ortaya koymuş bir yapım... Dizinin final bölümünden de anlayabileceğiniz üzere sadece ama sadece gerçeklik üzerine kurulu bir dizi.” (www.dizilab.pw, Erişim Tarihi: 03.11.2019)

\section{engineer16}

"baştan sona kadar gerçek bir hayatla karşı karşıyasınız..." (www.dizist.net, Erişim Tarihi: 07.11.2019)

\section{sytomrdmr}

"inanılmaz ve tamamen çok gerçekçi anlatmış. amerikanın sokaklarını bilen biri olarak söylüyorum hayran kaldım.” (www.dizist.net, Erişim Tarihi: 07.11.2019)

\section{kadırgalı}

Benim için dünyanın en realist, en kasvetli dizisidir. Hani gerçekçilik saçma sahneleri olmayan bir dizi izlemek istiyorsanız izleyebilirsiniz" (www.dizilpub.net, Erişim Tarihi: 05.11.2019)

\section{Fatih}

"Realitenin tavan yaptığı dizidir..." (www.dizilpub.net, Erişim Tarihi: 05.11.2019)

\section{Edo G}

“Gerçekçilik üst düzey” (www.dizilpub.net, Erişim Tarihi: 05.11.2019)

\section{İlker uzun}

“Arkadaşlar bu dizi diğer popüler diziler kadar ön planda olmayan bir dizi fakat oyunculuklar olsun, kurgu olsun, gerçekçilik olsun her açıdan kendine bağlayan bir dizi niteliğinde..." (www.dizilpub.net, Erişim Tarihi: 05.11.2019)

\section{Umut}

"Biri gerçeklik mi dedi? Klişelerden uzak, her ne kadar Baltimoreda geçse de sizi kolaylıkla bu gerçekliğe çeken bir yapıt. Sabıkalı torbacıların dizi de bölümlerce oynaması buna en net örnek olabilir..." (www.dizilpub.net, Erişim Tarihi: 05.11.2019)

\section{Heisenberg}

"Dizinin ilk sezonunu yeni bitirdim.Şuanlık diyebilirim ki gerçekçilik bakımın çok iyi..." (www.dizilpub.net, Erişim Tarihi: 05.11.2019)

\section{Tema-2: Duygusal İfade}

Yorumlara ilişkin yapılan analizde izleyicilerin ağlama, aşırı öfke, aşırı sevinç, sevgi veya gerçek hayattan kopacak derecede bağlanma gibi duygusal ifadeleri (Emotional Expression) kullandıkları görülmüştür. İncelenen dizilerin tamamında, yorum yapan izleyicilerin birden 
fazlasının, dizi bittikten sonra kendisini boşlukta hissettiğine ilişkin beyanlarının olduğu da dikkat çekmiştir. İzleyicilerin bazılarının karakterin canlandırdığı öldürme sahnelerine ilişkin yorumlarında ise bizzat dizideki katil karakteri ile kendilerini özdeşleştirdikleri ve gerçek hayatla ilişkilendirdikleri görülmüştür.

İzleyicilerin bazılarının, dizilerle ilgili, internet siteleri üzerinden yaptıkları, bu tema kapsamındaki bazı yorumları ve nick nameleri aşağıdadır:

\section{1- Breaking Bad}

\section{Deprix}

"Keşke hafizamı kaybetsem de tekrar izlesem dedigim efsane." (www.dizilab.pw, Erişim Tarihi: 03.11.2019)

\section{Doctor W}

“...Sizi atmosferinin içine alıyor hatta sizde saçınızı kazıtıp, böyle bir sakal şekli yapıp, bu işlere girmek istiyorsunuz..." (www.dizilab.pw, Erişim Tarihi: 03.11.2019)

\section{Hauzbaus}

“...Finalden sonra ben bu kadar ağladığımı bu kadar üzüldüğümü hatırlamıyorum. Tarihin en iyisi dizisiydi ama bitince verdiği acı çok büyük. Dizi boyunca kime kızıcam kimi sevicem bilemedim inanılmaz bir olay örgüsü var çok ince ayrıntılar vardı bu da diziyi efsane yaptı mükemmeldi ama bıraktığı yara çok büyük bitmesi çok acı..." (www.dizilab.pw, Erişim Tarihi: 03.11.2019)

\section{Edebiyatci}

"Bir diziyi hem izleyip bitirmek isteyip hem de biteceğini bile bile bitmesini istememek, finalden sonra istemsizce ağlamak..... Diziyi bitirdim ama hayatımda sanki büyük bir boşluk oldu. Bu boşluk acaba hangi Walter White karakteri doldurur bilemiyorum.” (www.dizilab.pw, Erişim Tarihi: 03.11.2019)

\section{Platinium}

"Geçen ay bitirdim ve hala boşluktayım..." (www.dizilab.pw, Erişim Tarihi: 03.11.2019)

\section{2- Dexter}

\section{thejok}

“Geçen ay bitirdim ve hala boşluktayım...” (www.dizilab.pw, Erişim Tarihi: 03.11.2019)

\section{Imperius}

"İzlerken içinize işliyor, dizideki duyguları hissedebilirsiniz karakterler şaşırdığında, mutlu olduğunda ya da üzüldüğünüzde aynısını hissetmemeniz mümkün değil. Bitirdiğinizde ayrılık acısı çekermiş gibi etkileri olabilir. I miss you Dexter.” (www.dizilab.pw, Erişim Tarihi: 03.11.2019)

\section{elifoguzkan}

"o kadar alışmışım ki resmen her şeyim olmuş. Abarttığımı düşünenler vardır ama şuan sanki her şeyim beni bırakıp gitmiş gibi.. unutulmayacaksın Dex. \" (www.dizilpub.net, Erişim Tarihi: 05.11.2019)

\section{Zorbamanifesto}

"Diziyi bitireli bir hafta oldu. Hayatım da tarif edemediğim bir boşluk var. Kafayı yastığa koyar koymaz aklıma geliyor.” (www.dizilpub.net, Erişim Tarihi: 05.11.2019) 


\section{Mustafa Can KIVRAK}

"Şöyle söyleyeyim bir dizi ki bu dexter adamı içten bağlıyo, hapsediyo. Acıyı ,sevinci,üzüncü, inceyi biz dexterla beraber yaşadık $:-$ ” (www.dizilpub.net, Erişim Tarihi: 05.11.2019)

\section{coxcomb}

"Bir seri katile bu kadar alışılır onca bölümden sonra bittiğinde kendimi bir boşlukta hissettim çok duygulandım” (www.dizilab.pw, Erişim Tarihi: 03.11.2019)

\section{@Agathusian}

“...dizinin akışına kendimi bıraktım ve kendimi'de şuan inandırmak zorunda olduğum bir sürede bitirdim diziyi.. 8 sezon, 96 bölüm, 4320 dakika, 72 saat.. Sadece 2 hafta içerisinde ve tam olarak şuan bitirdim.. duyguları taze olan ve bu tazelikle, bu yorumu yapan bana inanın ve yavaş izleyin.. Bittiğinde hemen yeni bir dizi arayacaksınız, üzüleceksiniz, boşlukta hissedeceksiniz ve biraz öfkeleneceksiniz.. "Dexter" harcanın zamanın değerini hissettiren bir dizi.. Vakti kıymetli bulan biri olarak Dexter için harcamış olduğum 72 saatim için fazlasıyla mutluyum.." (www.dizibox.pw, Erişim Tarihi: 06.11.2019)

\section{Viktormy}

“Dünyanın en iyi niyetli katili.” (www.dizilab.pw, Erişim Tarihi: 03.11.2019)

\section{oceanic}

03.11.2019)

"bir katili bu kadar seveceğimi düşünmezdim" (www.dizilab.pw, Erişim Tarihi:

\section{thewoman}

"Bir insan bir katili bu kadar sempatik hale getirebilir...Öyle bir dizi düşünün ki hem bittiği için üzülüyor,belki de günlerce kahroluyorsunuz" (www.dizilab.pw, Erişim Tarihi: 03.11.2019)

\section{-Dexter}

"Bir Seri Katil bukadar sevilebilirdi." (www.dizilab.pw, Erişim Tarihi: 03.11.2019)

\section{Enigma}

"Bittiğinde boşluğa düştüğüm manyak gibi üzüldüğüm bi diziydi.Sonuçta dizi dimi niye üzülür bi insan.İşte Dexter öyle bi tipti.Özlüyoruz,üşüyoruz reyiz..” (www.dizilab.pw, Erişim Tarihi: 03.11.2019)

\section{DiziEmektar}

"İnsanların psikolojilerini etkiliyebilir sizi 2 kere düşündürtmez 5 kere düşüntürdür bu dizi Efsane..." (www.dizilab.pw, Erişim Tarihi: 03.11.2019)

\section{TheBlackWaltz}

“...karakterin iç sesi falan sizi karakterle özleştiriyor bazı bölümlerde dexter yakalanacak diye ben dexterden fazla gerildim" (www.dizilab.pw, Erişim Tarihi: 03.11.2019)

\section{marvelvdc}

"Benim hayatımda izlediğim en efsane dizi bittikten sonra depresyona girdim..." (www.dizilab.pw, Erişim Tarihi: 03.11.2019) 


\section{ixiir}

“bitti biteli sabah kahvaltı yapmıyorum” (www.dizilab.pw, Erişim Tarihi: 03.11.2019)

\section{chanel candy}

"Hayatımda "uf ne güzel yaptın bir kez benim için " dediğim ilk seri katilsin Dexter Morgan." (www.dizilab.pw, Erişim Tarihi: 03.11.2019)

\section{heisenberg}

"Utanmadan sevdiğimiz ilk seri katil.” (www.dizilab.pw, Erişim Tarihi: 03.11.2019)

\section{3- $\quad$ Sherlock}

\section{@Gulten95}

"Off Sherlock çok güzeldin bee.. bizi aptal gibi hiss etdirdin uzun uzun düşündürdün.." (www.dizibox.pw, Erişim Tarihi: 06.11.2019)

\section{@ugur@box}

"eşi benzeri yok, duygudan duyguya geçiyorum, her saniyesinde kendimi daha aptal hissediyorum, sherlock un ne konuşma hızına ne de düşünme hızına yetişme imkanı yok..." (www.dizibox.pw, Erişim Tarihi: 06.11.2019)

\section{svlgktrk}

"kendinizi aptal hissettirecek bir yapım izlemeden duramıorsunuz." (www.dizilpub.net, Erişim Tarihi: 05.11.2019)

\section{alpagon}

"Beyin yakan bi yapım, kendinizi aptal hissetmeniz çok normal, ama gündelik hayatta bu dizinin faydasını görürsünüz $:-)$ " (www.dizilpub.net, Erişim Tarihi: 05.11.2019)

\section{white nigga1}

"arada bir kendinizi aptal hissetmeniz hariç kusursuz bir dizi" (www.dizimag.pw, Erişim Tarihi: 04.11.2019)

\section{Diziizlemeyegeldim}

"alt yazıları kaçırıyom...dizideki olay örgüsünün hepsini anlamam mümkün değil zaten sherlock'un söylediklerini de zar zor yarısını anlıyorum galiba aptalım" (www.dizimag.pw, Erişim Tarihi: 04.11.2019)

\section{seftaliliseyler}

"Hayatimda hicbir zaman birine/bir seye karsi boyle bağlanmadım...Sen mukemmel bir seysin Sherlock Holmes!" (www.dizilpub.net, Erişim Tarihi: 05.11.2019)

\section{4- $\quad$ The Wire}

\section{Efe Sığırcı}

"Final bölümünün nasıl hızlı geçtiğini anlatamam, son saniyesinde bile kendimi bir boşlukta hissetmeye başladım." (www.dizilpub.net, Erişim Tarihi: 05.11.2019)

\section{Tema-3: Kurgusal Atıf}

Kurgusal atıf (Fictional Attribution) kavramı ile; izleyicilerin kurgusal olarak kendilerine sunulan içeriği, olayları, karakterleri gerçek hayata atfetmesini, aktarmasını, düşüncelerinin, tutumlarının bu yönde değişmesini ve hatta gündelik hayatlarının akışını etkileyecek derecede 
bilişsel yapılarının ve davranışlarının etkilenmesi durumunu ifade edilmektedir. $\mathrm{Bu}$ anlamda kavram, gerçek hayata, kurgusal dünyadan yapılan atıfları karşılamak için kullanılmıştır.

İzleyicilerin bazılarının, dizilerle ilgili, internet siteleri üzerinden yaptıkları, bu tema kapsamındaki bazı yorumları ve nick nameleri aşağıdadır:

\section{1- Breaking Bad}

\section{Cocodancer}

"antep de küçük bi anahtarcı dükkanım var bu dizi başlamadan önce 20-25 tl kazanacam diye kendimi heba eder.faturaları kirayı düşündükçe de sıkıntıya girerdim.fakat diziye başladıktan sonra inanın müşteri gelmesini istemez oldum.bi çok işe ya gitmedim,yada olabildiğince çabuk ve baştan savma yapıp geldim.bi çok müşteri kaybettim.ve tabi para beni tanıyan bazı müşteriler işime önem vermediğim için bi daha bana iş yaptırmaz oldu.sonuç olarak iflas ettim. 1 hafta içinde dükkanı kapatacağım.peki deydimi derseniz bence sonuna kadar.” (www.dizilab.pw, Erişim Tarihi: 03.11.2019)

\section{Nuzhet}

"House dizisinde saçma sapan nedenlerden eczacılara kitliyolardı. Bu diziyi izlerken eczacı olmanın bir ayrıcalığı olduğunu anlıyorsun.” (www.dizilab.pw, Erişim Tarihi: 03.11.2019)

\section{Costwo}

"lisede işlenen kimya derslerinde, bu diziyi derslerle birlikte verseler çocuklar aydınlanır... öğretmenin veli toplantısında" kafa var ama çalışmıyor, çalışsa yapar" dediği öğrencileri o zaman görün bide. çocuklarda kafa var, vizyon yok.” (www.dizilab.pw, Erişim Tarihi: 03.11.2019)

\section{2- Dexter}

\section{Mr.BigBoss}

"İzlerken acaba benden de katil olurmu düşüncesi gelir insana ve henüz daha izlememiş insanları kıskanıyorum diziye başlarken alacakları o duygu... özellikle dizide dexterin iç sesine kapılır gidersiniz." (www.dizilab.pw, Erişim Tarihi: 03.11.2019)

\section{Ferhat007}

“izlemeyin... insanın katil olası geliyor.” (www.dizilab.pw, Erişim Tarihi: 03.11.2019)

\section{uygarkara}

"Türkiyenin ilk seri katili Dexter hayranıymış.. Adam akıllı ama bir o kadar da aptalmış. Dexter bu dizi de İyi insanları öldüren kötü adamları öldürüyor. Yani seri katilden çok halk kahramanı. Bizim seri katil de vatandaşlara dadanıyor. Hepimizin izlediği dizi kahramanının iyi taraflarından çok kötü gözüken taraflarını kendine idol olarak almış arkadaş" (www.dizilab.pw, Erişim Tarihi: 03.11.2019)

\section{Sadık Yoda}

"gelmiş geçmiş en cool karizmasının "aman öldür s.ğü hakketti k..pe kezzap'ta dök tam olsun üstad"gibi piskopat sözler söyleyip bi katile hayran kalmak bu dizi sayesinde normalleşiyor..." (www.dizilab.pw, Erişim Tarihi: 03.11.2019)

\section{jubilantboy}

"Eminim herkesinde içinde bir Dexter reis vardır.. Gunluk hayatta ortaya cıkaramazsakta izlerken az da olsa tatmin ettiriyor. Her sehire lazımsın Dexter Reyiiz.." (www.dizilab.pw, Erişim Tarihi: 03.11.2019) 
talhatekinn

03.11.2019)

“INSSANIN SERI KATIL OLASI GELIYOR" (www.dizilab.pw, Erişim Tarihi:

\section{Ece_Nefsgldi}

"seri katil olasım geliyo bi an..." (www.dizilab.pw, Erişim Tarihi: 03.11.2019)

\section{offfflinee}

“izlerken adeta seri katil olasım geliyor” (www.dizilab.pw, Erişim Tarihi: 03.11.2019)

\section{umutbarisbasol}

"İzledikten sonra seri katil olmak isteyebileceğiniz bir dizi." (www.dizilab.pw, Erişim Tarihi: 03.11.2019)

\section{chichi} 03.11.2019)

“ "iște benim olmak istediğim katil bu" dedirten adam.” (www.dizilab.pw, Erişim Tarihi:

\section{fffffundaaaaa}

"Seri katillerin en bitanesi ) hadi öldür artik dexxxx diye bagirdigimi hatirliorum" (www.dizilab.pw, Erişim Tarihi: 03.11.2019)

\section{KawaBanga}

"Bittikten sonra ingilizce münazaramız vardı.Uyuyamamıștım finali yüzünden.Mal gibi geziniyordum okulda.Öyle bir drama ki üzüntülü kalp atışlarına ve nefes dargınlığına sebep olabiliyor bazen.Şaşkınlığı bambaşka bir düzeye çıkartıyor.:/" (www.dizilab.pw, Erişim Tarihi: 03.11.2019)

\section{srtn}

“...kendileri benim aşık olduğum ilk adam ve seri katil... Sayesinde uzun bir süre ruhsuz ve duygusuz olarak dolaştım ve hiç pişman değilim. Ve bir kez daha yeni baştan almamam için hiç bir sebep yok." (www.dizilab.pw, Erişim Tarihi: 03.11.2019)

\section{DiziBagimlisi}

"Her şehire 5 er 10 ar koyacaksın böyle seri katilleri, bak bakalım sonra bir şey oluyor mu $\odot$ " (www.dizilab.pw, Erişim Tarihi: 03.11.2019)

\section{Nikolay Mihaylovic}

"Hayatıma "adalet" kavramını belirgin bir şekilde kazımıştır bu dizi." (www.dizilpub.net, Erişim Tarihi: 05.11.2019)

\section{Sbestederin}

"Bu diziye nasıl bu kadar geç başladım anlam veremiyorum kendime. Ne kadar güzel birşeyi kaçırmışım. Öncelikle DEXTER MORGAN karakteri benim hayatımın önemli bir yerinde hep varolacak... Debra'nın ölümü beni yıkıp geçti... Debra'nın ölümü ve Dex'in yüzündeki çaresizlik hala gözümün önünde.. Sabahın 05:00'ine kadar ağladım.” (www.dizilpub.net, Erişim Tarihi: 05.11.2019) 


\section{_scarface}

"DİKKAT BAĞIMLILIK YAPABİLİR (:) o adam öldürdükçe içim rahatlıyodu başka hiç bi dizide yaşayamadım bu hissi boşluğu dolmayan bi dizi." (www.dizilpub.net, Erişim Tarihi: 05.11.2019)

\section{cancakir}

"bitireli 1 yıl olmasına rağmen normal hayatımda bazı insanların hareketini deb'e benzetip duruyorum" (www.dizilpub.net, Erişim Tarihi: 05.11.2019)

\section{dexter}

"Bu nasıl bir dizidir Allahım Allahım..Dexter... İçindeki karanlığı, kötü insanları öldürerek tatmin edebilen kişi. Sempatik bir seri katilimiz. Duygudan yoksun fakat hayatı dramla dolu biri...Dexterin iç konuşmaları falan gerçekten beynimde canlanıyor. Onun sayesinde potansiyel katil olabilirim. iyi ki tek yaşamıyorum. Yoksa evin her yeri çöp poşeti ile dolu olurdu (:i)" (www.dizilpub.net, Erişim Tarihi: 05.11.2019)

\section{@Allabyyme}

“...Dexter iç canavarı ile olan konuşması size hayatı çok güzel öğretiyor ve bu arada insanları nasıl manipüle nasıl duygusuz olacağınızıda..." (www.dizibox.pw, Erişim Tarihi: $06.11 .2019)$

\section{3- $\quad$ Sherlock}

\section{1bBakerst}

"O kadar mükemmel bir dizi ki sizi içine çekiyor ve bittiğinde bi yakınınızı kaybetmiş gibi üzülürken buluyorsunuz kendinizi.” (www.dizilpub.net, Erişim Tarihi: 05.11.2019)

\section{EvaMorgan}

"Kendimi üzgün hissettiğimde, pc karşısında yemek yediğimde, büyük bir dizi boşluğunda olduğumda yeniden ve yeniden Sherlock izlerken kendimi buluyorum. Mutsuz günlerimin neşe kaynağı." (www.dizilab.pw, Erişim Tarihi: 03.11.2019)

\section{ozgeoztuncx}

"Film bittiğinde Yemek Yerken,Gezerken Tozarken adeta kendinizi Sherlock sanıyorsunuz" (www.dizilab.pw, Erişim Tarihi: 03.11.2019)

\section{Ygz_ass68}

"Bölümleri belki 1015 defa izledim. Yalan değil gerçekten her bölümü bir o kadar izlemişimdir. O kadar güzel ve iyi geliyor ki. Bölümleri izledikten sonraki hayat akışımı anlatmıyorum bile..." (www.dizilab.pw, Erişim Tarihi: 03.11.2019)

\section{Deadpool92}

"Bunu gururla söylüyorum.Diziyi evimde yüksek sesle izliyip dinliyordum.Arka tarafi bulunduğum odaya bakan bir okul var evimizin yan tarafinda.Artık kim duyduysa o gün bugündür okulun zil sesi Sherlock'un başlangıç fon müziği” (www.dizilab.pw, Erişim Tarihi: 03.11.2019)

\section{SenaTheUnicorn}

“...̇̇zledikten sonra insanlara daha dikkatli bakmaya başlıyorsunuz, çıkarım yapmaya çalışıyorsunuz..." (www.dizilab.pw, Erişim Tarihi: 03.11.2019) 


\section{anterka}

"hayatımın bir parçası oldu uzun süre izlendiğinde sherlock gibisin, farkına varmadan olmuşsun" (www.dizilab.pw, Erişim Tarihi: 03.11.2019)

\section{Laghima}

"Çok fazla izleyince gün içerisinde kendi kendinize Sherlock'culuk oynayasınız geliyor insanlara bakarak çıkarım yapmaya çalışmalar falan kendi kendinize düşünüyorsunuz bazen şimdi Sherlock olsam diye ama bu kadarıyla kalıyor fazla da şey etmemek lazım." (www.dizilab.pw, Erişim Tarihi: 03.11.2019)

\section{sleepingwithseries}

"ben Sherlock'u izlediğim her sene bi etrafımdakilerden bir şeyler bulmaya çalışıyorum. Yapamıyorum o ayrı konu jfsakfjas. Farkındalık kazandırıyor en azından" (www.dizilab.pw, Erişim Tarihi: 03.11.2019)

\section{4- The Wire}

\section{@ siyahatliprens}

"Gelmiş geçmiş en iyi diziler arasında olup sokakta uyuşturucu satan oyuncular bile gerçek hayatta ki tacirlerdir. Milletvekilinden polisine hatta başkana kadar uzayan müthiş yapımdır..." (www.dizibox.pw, Erişim Tarihi: 06.11.2019)

\section{Gökberk Bey}

“...Batı Baltimore'daki sahnelerde gerçekten o mahallede geziyormuşsun hissi... Muazzam derecede gerçekçi olması yüzünden heralde..." (www.dizilab.pw, Erişim Tarihi: 03.11.2019)

\section{siyahatlıprens}

"Yozlaşmış politikacılar,ihanet eden polisler, hiç bir oyunculuk kabiliyeti olmadan yıllarca eğitim alan oyunculara taş çıkaran kişiler, ihanetler, aşklar ve en önemlisi hayatın en acımasız yüzü.. Yaşınız kaç olursa olsun The Wire ölmeden izleyin." (www.dizilab.pw, Erişim Tarihi: 03.11.2019)

\section{Hakanyjkn}

"Suçun toplum, polis ve suçlu üzerinde yarattıklarına değinen, şahısların psikolojilerine değinerek suç kavramını derinlemesine bir şekilde inceleyen bu dizide aynı zamanda politik bir eleştiri de söz konusudur. Şahsen polislerin, bürokratik engellerden ötürü işlerini yapamamas1, kanun koruyucuların, kanunu korumak maksadıyla kanun dışı davranışlar sergilemesi ve siyasi kaygıların yansıtılması, mevcut sisteme dönük ciddi bir eleştiridir.” (www.dizilab.pw, Erişim Tarihi: 03.11.2019)

\section{tebevolimo1940}

“...toplum içindeki yozlaşmayı ve bürokratik engellemeleri çok güzel dile getiriyor.. çok ince ve güzel mesajlar var..." (www.dizilab.pw, Erişim Tarihi: 03.11.2019)

\section{Sonuç ve Tartışma}

$\mathrm{Bu}$ çalışmada suç temalı dizi filmlere ilişsin yapılan izleyici yorumları analiz edilerek bulunan 3 tema, popüler kültürün toplum üzerindeki etkisini göstermektedir. Yorum yapan izleyicilerin çoğunun, etkilendikleri dizi filmlerin karakterlerinden, sahnelerinden ve olay örgüsünden hareketle gerçek hayat ve kurgu arasındaki farkı ayırt etmede zorlandıkları görülmüştür. Birçok yorumda, gerçek hayatın dizi filmde yansıtıldığına inanıldığı ve hatta gerçek 
hayatta farkında olunamayan unsurların dahi dizi film aracılığıyla ancak farkına varılabildiği düşüncesinin hâkim olduğu görülmüştür. Bu kapsamdaki yorumlardan gerçek hayat ile simüle edilmiş gerçeklik arasındaki sınırın (gerçeklik eşiği) aşındığı ve hatta gerçekliğin yerine kullanılmaya başlandığı düşünülebilir.

Analiz edilen yorumlarda, izleyicilerin ağlama, aşırı öfke, aşırı sevinç, sevgi veya gerçek hayattan kopacak derecede bağlanma ifadeleri kullandıkları görülmüştür. Dizlere ilişkin olarak yapılan yorumlarda birden fazla izleyicinin, izledikleri filmlerin bitmesinin ardından kendisini boşlukta hissettiğine dair ifadeler kullandıkları dikkat çekmiştir. Dizi filmdeki suçluyu oynayan karakterlerle kendilerini özdeşleştirdikleri ve özellikle katil rolündeki karakterle empati kurarak, öldürmenin dahi haklı görüldügü ve destek verildiği ifadelere rastlanılmıştır.

Çalışmada, izleyicilerin kurgusal olarak kendilerine sunulan içeriği, olayları, karakterleri gerçek hayata atfettiği ifadeler dikkat çekmiştir. Bu açıdan yorumlarda, kurgusal olarak izledikleri karakterler, sahneler veya olay örgüsünü gerçek hayata aktardıkları ve hatta düşüncelerinin, tutumlarının bu yönde değiştĭgi, ayrıca gündelik hayatlarının akışını etkileyecek derecede bilişsel yapılarının ve davranışlarının etkilendiğini ifade ettikleri görülmüştür. Bu anlamda "Kurgusal atıf" kavramı ortaya konularak, gerçek hayata, kurgusal dünyadan yapılan atıfları karşılamak amaçlanmıştır. Kurgu ile gerçek arasındaki farkın ortadan kalmasıyla birlikte, kurguya ilişkin unsurların gerçek hayata aktarılmasını, atfedilmesini ifade etmektedir.

Popüler kültürün, gerçek hayatı sarıp sarmaladığı ve insanın bilişsel yapısını etkileyerek davranışlarına yön verdiği kabul edilebilir. Bu açıdan adli bilimlere ilişkin unsurların da diğer birçok şey gibi popüler kültürün malzemesi haline getirilmeye çalıșıldığ 1 ve hatta getirildiği düşünülebilir. $\mathrm{Bu}$ bağlamda izleyicilerin ekranda kendilerine sunulan ile gerçek hayata ilişkin değerlendirme, düşünce, tutum ve hatta davranışlarının değiştiği söylenebilir.

Gerçeğin simüle edilerek tekrar ve tekrar farklı biçimlerde sunulmasının, bir eğlendirme biçiminden öte bilişsel yapıyı ve toplumsal bakışı da değiştirdiği/değiştirebileceği varsayılabilir. Bu bağlamda film ve dizilerin buna katkı sağlayan başat faktörler olduğu söylenebilir. Araştırma evreninin geniş olması nedeniyle, ilerleyen çalışmalarda farklı örneklemler üzerinden yapılacak analizlerle bulguların artabileceği düşünülmektedir.

\section{Kaynakça}

Akyel, M., Çetli, E., Özkoçak, V. (2019). Adli Bilimler ve Adli Antroplojide Yeni Teknik ve Yöntemler. Recent Evaluation on Humanities \& Social Sciences. September 2019, No: 111. ISBN: 978-1-912503-72-8.

Arık, M. B. (2009). İnsan ve Toplumu Bir Arada Düşünmedikçe Popüler Kültürü Tartışamayız. Medya ve Popüler Kültür Eleştirel Bir Yaklaşım, 1-30. https://doi.org/10.31123/akil.460195.

Bolat, G., Mantar, N. (2019). Danışmanlık Tedbirinin Adli Bilimler ile İlişkisi. Akademik Sosyal Araştırmalar Dergisi. 6(34). 597-604. https://doi.org/10.16990/sobider.4790.

Christensen, L. B., Johnson, B., \& Turner, L. A. (2015). Araştırma Yöntemleri: Desen ve analiz. (Çev. Ahmet Aypay). Ankara: Anı Yayıncılık.

Cohen, B.C. (1963). The Press and Foreign Policy. Princeton University Press. Princeton.

Creswell, J. W. (2007). Qualitative inquiry \& research design: Choosing among five approaches ( 2. Bask1). USA: SAGE Publications.

Çetli, E., Koç, F., Özkoçak, V. (2019). Parmak İzi ve Yapay Sinir Ağları Sistemlerinin Gelişiminin Adli Bilimler Açısından İncelenmesi. Turkish Studies Cudes 2019. 14(5). 37-51. 
Çetli, E., Özkoçak, V. (2018). Use of Recorded Personal Data in Forensic Sciences. Avrasya Sanat ve Medeniyet Dergisi. Volume:10. 1-12.

Darıcı, S. (2015). Dijital Oyunlarda Kullanılan Subliminal Mesajların Gerçeklik Algısı Üzerindeki Etkilerine Yönelik Bir Çalışma: Gerçeklik Eşiği Kavramı. Turkish Studies International Periodical for the Languages, Literature and History of Turkish or Turkic, 181-202, https://doi.org/10.7827/turkishstudies.8778.

Koç, F. (2019). Yeniden Yüzlendirme (Fasiyal Rekonstrüksiyon) Uygulamarında Güncel Yaklaşımlar. Turkish Studies Cudes $2019 . \quad 14(5) . \quad 119-129$. https://doi.org/10.29228/turkishstudies.24977.

Mantar, N., Bolat, G., Bektaş, İ. (2019). Cinsel İstismar Vakalarının Çözümlenmesinde Adli Görüntü Analizinin Önemi. Turkish Studies Cudes 2019. Vol:14. Issue:5. 169-182. https://doi.org/10.29228/turkishstudies.24984.

Marcuse, H. (1964). One dimensional man, Boston (Beacon Press) 1964.

Neumann, W. (2003). Social research methods: Qualitative and quantitative approaches. Boston: Allynand Bacon.

Özkan, H. H. (2006). Popüler kültür ve eğitim. Kastamonu Eğitim Dergisi. 14(1). 29-38.

Özkoçak, V., Galip, A., Gültekin, T. (2017). Somatoskopi ve Antropometri Tekniklerinin Adli Bilimler için Önemi. Hitit Üniversitesi Sosyal Bilimler Enstitüsü Dergisi 10(2). 703-714. https://doi.org/10.17218/hititsosbil.328735.

Özkoçak, V., Özdemir, F. (2017). Anadolu Erkeklerine Ait Yüz Ölçümleri Arasındaki İlişkinin İncelenmesi. Avrasya Sosyal ve Ekonomi Araştırmaları Dergisi. C:4. S:11. 176-186.

Patton, M. Q. (1990). Qualitative evaluation and research methods. SAGE Publications, Inc.

Taşkın, D. (2019). Türkiye Göç Stratejisinin Olası Göç Karşısında Ulusal Güvenlik Yeterliliğinin $\begin{array}{lllll}\text { Analizi. Turkish } 2019 . & \text { 14(5). 23-239. }\end{array}$ https://doi.org/10.29228/turkishstudies.24983.

Tekeli, E., Çetli, E. (2019). Çocuklara Yöneltilen Cinsel İstismarın Hukuki Boyutu. Turkish Studies Cudes 2019. 14(5). 241-252. https://doi.org/10.29228/turkishstudies.25872.

Tellan, D. (2016). Mekân, Eğlence ve Popüler Kültür İlişkisini Değerlendirmek. TRT Akademi, Ĕ̈lence Endüstrisi Saylsı, 1(1), 136-153.

Yıldırım, A., \& Şimşek, H. (2013).Sosyal bilimlerde nitel araştırma yöntemleri.(9. Genişletilmiş Bask1) Ankara: SeçkinYayınevi.

Yin, R. K. (2003). Case study research: Design and methods (Vol. 5). Thousand Oaks, CA: Sage.

\section{İnternet Kaynakları}

www.dizilpub.net, Erişim Tarihi: 05.11.2019

www.dizibox.pw, Erişim Tarihi: 06.11.2019

www.dizilab.pw, Erişim Tarihi: 03.11.2019

www.dizimag.pw, Erişim Tarihi: 04.11.2019

www.dizist.net, Erişim Tarihi: 07.11.2019 